\title{
Valproic Acid-Induced Hyperammonemia in the Elderly: A Review of the Literature
}

\author{
Vikrant Mittal, ${ }^{1}$ Sunanda Muralee, ${ }^{2}$ and Rajesh R. Tampi ${ }^{2}$ \\ ${ }^{1}$ Parkland Health Center, 1103 West Liberty Street, Farmington, MO 63640, USA \\ ${ }^{2}$ Yale New Haven Psychiatric Hospital, 184 Liberty Street, New Haven, CT 06519, USA \\ Correspondence should be addressed to Rajesh R. Tampi, rajesh.tampi@yale.edu
}

Received 8 April 2009; Accepted 6 July 2009

Recommended by George Kuchel

Valproic acid and its derivatives are commonly used to treat many psychiatric conditions in the elderly. Hyperammonemia is a less common but important side effect of these drugs. The elderly patient appears highly vulnerable to this side effect of this group of medications. In this paper, we systematically review the published literature for hyperammonemia induced by valproic acid and its derivatives. We describe the three reported cases and review possible treatment strategies for this condition.

Copyright () 2009 Vikrant Mittal et al. This is an open access article distributed under the Creative Commons Attribution License, which permits unrestricted use, distribution, and reproduction in any medium, provided the original work is properly cited.

\section{Introduction}

Valproic acid is a broad-spectrum antiepileptic drug that is approved for the treatment of several types of seizures. It is also prescribed for the treatment of bipolar disorder, schizoaffective disorder, social phobias, neuropathic pain, and for the prophylaxis and treatment of migraine headaches [1]. Valproic acid and its derivatives have been found to be useful and generally safe in the treatment of bipolar affective disorder, agitation in dementia, and refractory anxiety disorders in the elderly [2-4]. These drugs are known to cause hyperammonemia and associated encephalopathy, but most of this data comes from children and younger adults [5-10]. However, recent case reports have highlighted the fact that this complication can also occur in elderly $[4,11$, 12]. In this paper, we review the published literature on the occurrence of valproic acid-induced hyperammonemia in the elderly.

\section{Ammonia, Hyperammonemia, and Hyperammonemic Encephalopathy}

Amino acids, products of protein breakdown, are usually metabolized in the liver by transaminases and oxidative deaminases to produce ammonia [13]. Ammonia is then converted to urea and excreted through the kidney. The most important enzyme in the incorporation of ammonia into the urea cycle is carbomylphosphatase synthetase I (CPS I) [14].
Ammonia is also produced in the kidneys by the conversion of glutamine to glutamate by the enzyme glutaminase [11].

Hyperammonemia is a condition characterized by elevation in the serum level of ammonia above 40 mmols/L [15]. It is commonly caused by liver disease or inborn errors of metabolism [16]. Other less common causes are hyperinsulinemic hypoglycemia, carnitine deficiency, malignancies like leukaemias and myelomas, portosystemic shunts, urinary infections, surgeries, and parenteral nutrition $[12,13,17-$ 20]. Medications like 5-fluorouracil, salicylate, asparaginase, acetazolamide, diuretics, and valproic acid and its derivates have also been implicated in the development of this condition [5, 21-24]. However, an elevation in serum ammonia level above $200 \mathrm{mmols} / \mathrm{L}$ is more commonly seen in inborn errors of metabolism like urea cycle defects and branch chain organic acidaemias, although rarely other conditions may cause such high blood levels [25]. Although, hyperammonemia is thought to be associated with liver disease, most cases present with normal liver function $[10,26]$.

Mild and transient hyperammonemia can often be asymptomatic and is usually triggered by protein loads and catabolic states [13]. In symptomatic cases, the clinical features may be variable and episodic [13]. Many cases present with acute mental status changes characterized by confusion, personality change, irritability, ataxia, visual disturbance, lethargy, and somnolence [13]. They may also present with nausea, vomiting, or hyperventilation. More severe cases can lead to encephalopathy characterized by stupor and 
coma [27-30]. Although, most patients recover even from multiple episodes of hyperammonemic encephalopathy, it may occasionally lead to brain damage [31-33]. In severe untreated cases, seizures and death can occur due to raised intracranial pressure [13].

The pathogenesis of hyperammonemic encephalopathy remains unclear. Changes in mental status are thought to be due to high levels of ammonia and the presence of other organic acids. The brain ammonia concentration can be high even when the serum ammonia level is normal [5]. Hyperammonemia can also cause encephalopathy by inhibition of glutamate uptake by astrocytes [14, 34, 35]. As with delirium, elderly patients may present with several concomitant predisposing factors for developing hyperammonemia and encephalopathy $[4,36]$. These include agerelated cerebral changes like a more permeable blood brain barrier, alterations in stress-regulating neurotransmitters, and intracellular signal transduction systems $[4,36]$. Other risk factors include multiple medical problems, such as renal failure or hypoalbuminemia, or concomitant administration of topiramate, cimetidine, and aspirin, that may elevate the free fraction of valproate and increase the risk of hyperammonemia even in the absence of metabolic defect in the urea cycle [4]. With age, protein binding and certain liver functions decrease, leading to decreased plasma albumin, hepatic oxidation, and hepatic cytochromes such as P450-3A4 [4]. Concomitant administration of antiseizure medications such as phenytoin and phenobarbital may also increase the risk of hyperammonemia and should be used with caution [4]. In order to reduce the morbidity and mortality from this condition, vigilance for risk factors, early diagnosis, and prompt treatment are paramount [14].

It has been found that routine laboratory investigations are often not helpful in the diagnosis [13]. Although higher ammonia levels are associated with encephalopathy, blood levels of ammonia do not often correlate with the clinical condition [37]. It is important to ensure that serum ammonia levels are accurately measured as faulty storage and transport can lead to hemolysis and erroneous elevations in serum ammonia level [13]. Heparinised venous samples should be obtained and specimens should promptly be sent to the laboratory on ice or in a vacuum tube [13].

In patients with encephalopathy, cerebrospinal fluid (CSF) glutamine levels and EEG may aid in the diagnosis. A study of seven patients, ages $17-58$ years, with valproate induced hyperammonemic encephalopathy (VHE), showed that elevation of CSF glutamine and the changes in the EEG correlated moderately well with the time course of the encephalopathy [14]. All patients had medically refractory seizures. Five patients had been initiated on valproate therapy shortly before developing signs and symptoms of VHE. Three of these patients had previously taken valproate without substantial adverse effects and two had never before received valproate. Two other patients had taken valproate for an extended period, but received a dosage increase before the onset of VHE. Dose of valproate ranged from $500 \mathrm{mg} /$ day to $6500 \mathrm{mg} /$ day, although the doses of valproate for 2 of the cases were uncertain. The valproate levels varied from $33-199 \mathrm{mg} / \mathrm{dL}$ and the ammonia levels were between 19-
$750 \mathrm{mmols} / \mathrm{L}$ ). All patients in the study had EEG changes showing slow background waves with or without triphasic waves. CSF glutamine level was elevated in $80 \%$ of the patients with only $71 \%$ of patients having an elevated venous ammonia level. CT scan or MRI may aid in the diagnosis of encephalopathy [38]. These studies may reveal cerebral edema, although this is not a very consistent finding [39-41].

\section{Methods}

We searched the following databases: Ovid MEDLINE (http://gateway.tx.ovid.com/gw2/ovidweb.cgi) from 1950 to June Week 3 2009, EBM Reviews-Cochrane Database of Systematic Reviews 2nd Quarter 2009, PsycINFO 1967 to June Week 32009 with keywords "divalproex sodium," "valproate," "valproic acid," and "divalproate," "hyperammonemia," "hepatic encephalopathy," "urea cycle disorder," "liver failure," "aged," and "elderly." For the purpose of this paper, we considered anyone over the age of 60 years as "aged" or "elderly." We only considered reports from peer reviewed English language journals for this review. For standardization purpose, we used micromols/liter (mmols/L) for ammonia level and milligrams/deciliter $(\mathrm{mg} / \mathrm{dL})$ for valproic acid level. Also, the terms "valproic acid" and "valproate" have been used synonymously.

\section{Results}

Most of the reported cases of valproate induced hyperammonemia are in children and younger adults. To date, there are only four reported cases of hyperammonemia in the elderly in the medical literature $[4,11,12,42]$. Three major trials using valproic acid and its derivatives for the treatment of behavioral disturbance in dementia did not report hyperammonemia as a side effect. In these trials, sedation and urinary tract infection occurred more frequently in patients treated with valproic acid than in controls. Due to the differences in identifying adverse effects it was not possible to pool other observations concerning adverse effects between these studies [42].

The first reported case involved an 88-year-old African American man who presented with confusion after being treated with valproate at $250 \mathrm{mg}$ qid for seizure disorder of unknown etiology [4]. He had high ammonia levels $(836 \mathrm{mmols} / \mathrm{L})$ despite normal liver function tests and valproate level $(48 \mathrm{mg} / \mathrm{dL})$. The confusion resolved once that the valproate was discontinued and phenytoin was started. The confusion returned once that the valproate was reinitiated at $250 \mathrm{mg}$ po qid. The ammonia level during the second trial was $130 \mathrm{mmols} / \mathrm{L}$ and it decreased to $60 \mathrm{mmols} / \mathrm{L}$ once the valproate was discontinued.

McCall and Bourgeois reported a case in a 62-yearold person with brain aneurysm repair resulting in seizure disorder and being treated with divalproex sodium $250 \mathrm{mg}$ tid [12]. The patient presented with a one-week history of confusion, mumbling speech, dizziness, lethargy, and weakness. The valproate levels were within normal range at $75 \mathrm{mg} / \mathrm{L}$. The CT scan revealed increased size of the 
ventricles, sulci, and cisternal spaces with volume lossmildly prominent for age. Ammonia levels were elevated at $99 \mathrm{mmols} / \mathrm{L}$. The urinalysis and blood tests were within normal levels. The next day, the valproate was stopped and within next 3 days the patient's mental status improved. No other medication was used to reduce the ammonia level.

The third case involved a 76-year-old white woman with a seizure disorder who was taking divalproex sodium at $750 \mathrm{mg}$ po tid [11]. She presented to the emergency room two months after treatment was initiated with divalproex, with a one week history of generalized weakness, confusion, nausea, and vomiting. She had normal liver function tests. The discontinuation of the divalproex sodium reduced the ammonia level from $211 \mathrm{mmol} / \mathrm{L}$ to $34 \mathrm{mmol} / \mathrm{L}$ within 11 days. The patient's mental status and physical functioning improved significantly after the divalproex was discontinued. She was then treated with gabapentin at $300 \mathrm{mg}$ po bid for her seizure disorder.

The fourth case involved a 76-year-old man with bipolar illness who had been successfully treated with divalproex for the past 11 years and with extended-release divalproex for the past 16 months. He had consistently done well, serum valproic acid level was generally in the 50 to $80 \mathrm{mg} / \mathrm{dL}$ range, and transaminases were never elevated. There was no evidence of delirium or other problems attributable to divalproex; there had been 1 normal serum ammonia level 4 years ago. He became acutely confused, lethargic, and near-mute; he also began to urinate on the floor and to repeatedly remove his prosthetic eye. He was admitted with a serum ammonia level of $214 \mathrm{mmols} / \mathrm{L}$. Serum valproic acid level was $73 \mathrm{mg} / \mathrm{dL}$, and transaminases and liver ultrasound were normal. No other source of delirium was found. Divalproex was discontinued and he was treated with lactulose, the delirium cleared, serum ammonia normalized within 72 hours, and he was discharged. The author indicates that the reasons for this patient's encephalopathy remain unclear as there were no medication changes, no divalproex dosage adjustments, no evidence of liver disease, and no dietary change. This report underscores the fact that hyperammonemic encephalopathy is not necessarily an early complication of valproate therapy [42].

\section{Discussion}

The risk factors for the development of valproic acid-induced hyperammonemia include higher doses of the medication, concomitant use of other antilepiliptics like topiramate, carnitine deficiency, and the presence of congenital abnormalities of urea cycle $[5,12,22,24,43]$. The male to female ratio appears to be equal, although conclusive data is lacking at this time [44].

The mechanism by which valproic acid and its derivatives produce hyperammonemia is unclear, although various mechanisms have been proposed [45]. In the kidney, these drugs can increase the transport of glutamine across the mitochondrial membrane, thus making it available for the production of ammonia [46]. Furthermore, valproic acid can stimulate the enzyme glutaminase to increase the conversion of glutamine to glutamate, thereby making it more available for the production of ammonia [24, 45, 47, 48].

Valproic acid and its derivatives are also thought to inhibit the enzyme, Carbamoylphosphate synthetase I (CPS I), thereby preventing the incorporation of ammonia into the urea cycle $[4,5,24,30,45,49]$. These drugs may inhibits $\mathrm{N}$ acetylglutamate, an activator of CPS I, that is, needed for the normal function of this enzyme $[50,51]$. They can increase the concentration of pyruvate, a potent inhibitor of CPS I which prevents the incorporation of ammonia into the urea cycle $[3,4,24,30,45,49]$.

Carnitine an important nutrient found in meat and dairy products is also essential for the metabolism of valproic acid [52]. Long-term treatment with valproic acid and its derivatives depletes the stores of carnitine, thus reducing the metabolism of the drug and increasing the risk for hyperammonemia $[45,53]$. This condition is more common in children less than 2 years of age, those with inborn errors of metabolism and those patients on a vegetarian diet [22].

In patients with hyperammonemia, valproate levels may often be normal and the symptoms do not necessarily correlate with the degree of hyperammonemia, so clinical correlation is paramount $[24,54,55]$. L-carnitine supplementation has been shown to improve the symptoms of valproate related toxicities and reduces mortality in patients with valproate induced hepatotoxicity [56-58]. The use of intravenous hydration, $60 \mathrm{gm}$ protein restriction, and lactulose $45 \mathrm{~mL}$ every 24 hours, in addition to stopping the valproate has been shown to reduce valproic acidinduced hepatotoxicity [58]. Monitoring of symptomatic patients remains clinical rather than based on the serum ammonia levels [12]. The primary treatment for most patients with valproic acid-induced hyperammonemia is the dose reduction or withdrawal of the offending drug, in which case, complete recovery often occurs within a few days $[4,56]$. Addition of L-carnitine supplementation to dose reduction strategies may aid in faster resolution of symptoms $[8,52]$.

\section{Conclusion}

In elderly patients, valproic acid-induced hyperammonemia assumes significance, as many of these patients have comorbid conditions that already decrease their quality of life [59]. With the growing use of valproic acid and other mood stabilizers in the management of psychiatric conditions in the elderly, it has become important for clinicians to be aware of more uncommon adverse effects of valproate.

A systematic review of literature indicates that there are four case reports documenting the development of hyperammonemia due to valproic acid and its derivatives in the elderly. Three of the four cases developed when valproate was used in the treatment of seizure disorder. The fourth case occurred in an elderly man treated successfully for bipolar illness with divalproex. As the mechanism of valproate induced hyperammonemia is multifactorial, it is important to be vigilant when using this medication in the elderly patients who have many comorbid conditions and concurrently use multiple drugs. 
Although the followup of the blood ammonia levels seems most intuitive in diagnosing hyperammonemia, often patients with elevated ammonia levels are asymptomatic $[24,54]$. The data to recommend routine checking of ammonia levels in all elderly patients treated with valproate is unavailable. However, available data indicates that ammonia levels should be checked and closely monitored in all elderly patients treated with valproate who develop altered mental status regardless of the duration of therapy and especially during periods of acute illness [42]. The efficacy of EEG and imaging techniques like brain CT and MRI scans in the diagnosis of symptomatic patients remains inconclusive $[14,38]$.

From the review of literature it appears that the best treatment measure for hyperammonemia from valproic acid and its derivatives is the dose reduction or discontinuation of the drug with or without supplementation of L-carnitine and providing symptomatic treatment for the patient. In the meantime, we should continue to carefully followup elderly patients treated with valproate and its derivatives for the development of sides effects like hyperammonemia.

\section{References}

[1] J. Wadzinski, R. Franks, D. Roane, and M. Bayard, "Valproateassociated hyperammonemic encephalopathy," Journal of the American Board of Family Medicine, vol. 20, no. 5, pp. 499502, 2007.

[2] D. L. Coulter, H. Wu, and R. J. Allen, "Valproic acid therapy in childhood epilepsy," Journal of the American Medical Association, vol. 244, no. 8, pp. 785-788, 1980.

[3] C. Lennkh and C. Simhandl, "Current aspects of valproate in bipolar disorder," International Clinical Psychopharmacology, vol. 15, no. 1, pp. 1-11, 2000.

[4] D. Feil, K. Chuang, and D. L. Sultzer, "Valproate-induced hyperammonemia as a cause of altered mental status," American Journal of Geriatric Psychiatry, vol. 10, no. 4, pp. 476-478, 2002.

[5] H. M. Hamer, S. Knake, U. Schomburg, and F. Rosenow, "Valproate-induced hyperammonemic encephalopathy in the presence of topiramate," Neurology, vol. 54, no. 1, pp. 230-232, 2000.

[6] S. Rawat, W. J. Borkowski Jr., and H. M. Swick, "Valproic acid and secondary hyperammonemia," Neurology, vol. 31, no. 9, pp. 1173-1174, 1981.

[7] Y. Ohtani, F. Endo, and I. Matsuda, "Carnitine deficiency and hyperammonemia associated with valproic acid therapy," Journal of Pediatrics, vol. 101, no. 5, pp. 782-785, 1982.

[8] G. P. Panikkar and S. M. Gilman, "Valproate-induced hyperammonemia in the psychiatric setting: 2 cases," Journal of Clinical Psychiatry, vol. 60, no. 8, pp. 557-559, 1999.

[9] C. A. Williams, S. Tiefenbach, and J. W. McReynolds, "Valproic acid-induced hyperammonemia in mentally retarded adults," Neurology, vol. 34, no. 4, pp. 550-553, 1984.

[10] B. S. Zaret, R. R. Beckner, A. M. Marini, et al., "Sodium valproate-induced hyperammonemia without clinical hepatic dysfunction," Neurology, vol. 32, no. 2, pp. 206-208, 1982.

[11] L. Mallet, S. Babin, and J. A. Morais, "Valproic acidinduced hyperammonemia and thrombocytopenia in an elderly woman," The Annals of Pharmacotherapy, vol. 38, no. 10, pp. 1643-1647, 2004.
[12] M. McCall and J. A. Bourgeois, "Valproic acid-induced hyperammonemia: a case report," Journal of Clinical Psychopharmacology, vol. 24, no. 5, pp. 521-526, 2004.

[13] N. D. Hawkes, G. A. O. Thomas, A. Jurewicz, et al., "Non-hepatic hyperammonaemia: an important, potentially reversible cause of encephalopathy," Postgraduate Medical Journal, vol. 77, no. 913, pp. 717-722, 2001.

[14] D. G. Vossler, A. J. Wilensky, D. F. Cawthon, et al., "Serum and CSF glutamine levels in valproate-related hyperammonemic encephalopathy," Epilepsia, vol. 43, no. 2, pp. 154-159, 2002.

[15] K. S. Roth, "Hyperammonemia," July 2008, http://www.emedicine.com/ped/TOPIC1057.HTM.

[16] C. D. Rudolph, A. M. Rudolph, M. K. Hostetter, G. E. Lister, and N. J. Siegel, "Inherited urea cycle and related disorders," in Rudolph's Pediatrics, pp. 618-631, McGraw Hill Medical Publishing Division, New York, NY, USA, 21st edition, 2003.

[17] R. H. Edwards, "Hyperammonemic encephalopathy related to ureterosigmoidostomy," Archives of Neurology, vol. 41, no. 11, pp. 1211-1212, 1984.

[18] R. M. Oliver, S. Talbot, and G. V. Raman, "Hyperammonaemic coma in ureterosigmoid urinary diversion," Postgraduate Medical Journal, vol. 65, no. 765, pp. 502-504, 1989.

[19] P. J. Hughes, P. D. W. Kiely, P. T. G. Davies, J. P. R. Dick, A. M. Turner, and R. J. M. Lane, "Hyperammonaemia-an important cause of encephalopathy: three case reports," Annals of Clinical Biochemistry, vol. 30, no. 2, pp. 225-227, 1993.

[20] D. N. Cruz and S. J. Huot, "Metabolic complications of urinary diversions: an overview," American Journal of Medicine, vol. 102, no. 5, pp. 477-484, 1997.

[21] N. Segura-Bruna, A. Rodriguez-Campello, V. Puente, and J. Roquer, "Valproate-induced hyperammonemic encephalopathy," Acta Neurologica Scandinavica, vol. 114, no. 1, pp. 1-7, 2006.

[22] J. Y. Raskind and G. M. El-Chaar, "The role of carnitine supplementation during valproic acid therapy," Annals of Pharmacotherapy, vol. 34, no. 5, pp. 630-638, 2000.

[23] K. H. Yeh and A. L. Cheng, "High-dose 5-fluorouracil infusional therapy is associated with hyperammonaemia, lactic acidosis and encephalopathy," British Journal of Cancer, vol. 75, no. 3, pp. 464-465, 1997.

[24] J. Duarte, S. Macias, F. Coria, E. Fernandez, and L. E. Claveria, "Valproate-induced coma: case report and literature review," Annals of Pharmacotherapy, vol. 27, no. 5, pp. 582-583, 1993.

[25] S. L. Chow, V. Gandhi, S. Krywawych, P. T. Clayton, J. V. Leonard, and A. A. M. Morris, "The significance of a high plasma ammonia value," Archives of Disease in Childhood, vol. 89, no. 6, pp. 585-586, 2004.

[26] W. R. Treem, "Inherited and acquired syndromes of hyperammonemia and encephalopathy in children," Seminars in Liver Disease, vol. 14, no. 3, pp. 236-258, 1994.

[27] E. Eze, M. Workman, and B. Donley, "Hyperammonemia and coma developed by a woman treated with valproic acid for affective disorder," Psychiatric Services, vol. 49, no. 10, pp. 1358-1359, 1998.

[28] H. Ichikawa, T. Amano, K. Kawabata, M. Kushiro, Y. Nagake, and H. Making, "Fatal hyperammonemia in a patient with systemic lupus erythematosus," Internal Medicine, vol. 37, no. 8, pp. 700-703, 1998.

[29] A. Kifune, F. Kubota, N. Shibata, T. Akata, and S. Kikuchi, "Valproic acid-induced hyperammonemic encephalopathy with triphasic waves," Epilepsia, vol. 41, no. 7, pp. 909-912, 2000. 
[30] W. N. Raby, "Carnitine for valproic acid-induced hyperammonemia," American Journal of Psychiatry, vol. 154, no. 8, pp. 1168-1169, 1997.

[31] J. E. Finkelstein, E. R. Hauser, C. O. Leonard, and S. W. Brusilow, "Late-onset ornithine transcarbamylase deficiency in male patients," Journal of Pediatrics, vol. 117, no. 6, pp. 897$902,1990$.

[32] N. E. Maestri, S. W. Brusilow, D. B. Clissold, and S. S. Bassett, "Long-term treatment of girls with ornithine transcarbamylase deficiency," New England Journal of Medicine, vol. 335, no. 12, pp. 855-859, 1996.

[33] M. Msall, M. L. Batshaw, R. Suss, et al., "Neurologic outcome in children with inborn errors of urea synthesis. Outcome of urea-cycle enzymopathies," New England Journal of Medicine, vol. 310, no. 23, pp. 1500-1505, 1984.

[34] D. D. Stadler, J. F. Bale Jr., C. A. Chenard, and C. J. Rebouche, "Effect of long-term valproic acid administration on the efficiency of carnitine reabsorption in humans," Metabolism, vol. 48, no. 1, pp. 74-79, 1999.

[35] I. Suárez, G. Bodega, and B. Fernández, "Glutamine synthetase in brain: effect of ammonia," Neurochemistry International, vol. 41, no. 2-3, pp. 123-142, 2002.

[36] J. V. Laurila, M. L. Laakkonen, J. V. Laurila, S. E. Timo, and T. S. Reijo, "Predisposing and precipitating factors for delirium in a frail geriatric population," Journal of Psychosomatic Research, vol. 65, no. 3, pp. 249-254, 2008.

[37] S. W. Brusilow, "Hyperammonemic encephalopathy," Medicine, vol. 81, no. 3, pp. 240-249, 2002.

[38] S. Ziyeh, T. Thiel, J. Spreer, J. Klisch, and M. Schumacher, "Valproate-induced encephalopathy: assessment with MR imaging and ${ }^{1} \mathrm{H}$ MR spectroscopy," Epilepsia, vol. 43, no. 9, pp. 1101-1105, 2002.

[39] R. H. Edwards, "Hyperammonemic encephalopathy related to ureterosigmoidostomy," Archives of Neurology, vol. 41, no. 11, pp. 1211-1212, 1984.

[40] R. M. Oliver, S. Talbot, and G. V. Raman, "Hyperammonaemic coma in ureterosigmoid urinary diversion," Postgraduate Medical Journal, vol. 65, no. 765, pp. 502-504, 1989.

[41] P. J. Hughes, P. D. W. Kiely, P. T. G. Davies, J. P. R. Dick, A. M. Turner, and R. J. M. Lane, "Hyperammonaemia-an important cause of encephalopathy: three case reports," Annals of Clinical Biochemistry, vol. 30, no. 2, pp. 225-227, 1993.

[42] J. T. Stewart, "A case of hyperammonemic encephalopathy after 11 years of valproate therapy," Journal of Clinical Psychopharmacology, vol. 28, no. 3, pp. 361-362, 2008.

[43] E. Longin, M. Teich, W. Koelfen, and S. König, "Topiramate enhances the risk of valproate-associated side effects in three children," Epilepsia, vol. 43, no. 4, pp. 451-454, 2002.

[44] M. Raja and A. Azzoni, "Valproate-induced hyperammonaemia," Journal of Clinical Psychopharmacology, vol. 22, no. 6, pp. 631-633, 2002.

[45] A. Verrotti, D. Trotta, G. Morgese, and F. Chiarelli, "Valproateinduced hyperammonemic encephalopathy," Metabolic Brain Disease, vol. 17, no. 4, pp. 367-373, 2002.

[46] J. M. Warter, C. Brandt, C. Marescaux, et al., "The renal origin of sodium valproate-induced hyperammonemia in fasting humans," Neurology, vol. 33, pp. 1136-1140, 1983.

[47] L. Rumbach, G. Cremel, C. Marescaux, J. M. Warter, and A. Waksman, "Valproate-induced hyperammonemia of renal origin. Effects of valproate on glutamine transport in rat kidney mitochondria," Biochemical Pharmacology, vol. 38, no. 22, pp. 3963-3967, 1989.
[48] A. M. Marini, B. S. Zaret, and R. R. Beckner, "Hepatic and renal contributions to valproic acid-induced hyperammonemia," Neurology, vol. 38, no. 3, pp. 365-371, 1988.

[49] G. L. Jones, F. Matsuo, J. R. Baringer, and W. H. Reichert, "Valproic acid-associated encephalopathy," Western Journal of Medicine, vol. 153, no. 2, pp. 199-202, 1990.

[50] H. Takahashi, R. C. Koehler, S. W. Brusilow, and R. J. Traystman, "Inhibition of brain glutamine accumulation prevents cerebral edema in hyperammonemic rats," American Journal of Physiology, vol. 261, pp. H825-H829, 1991.

[51] P. C. Champe and R. A. Harvey, Eds., Lippincott's Illustrated Reviews: Biochemistry, J. B. Lippincott, Philadelphia, Pa, USA, 2nd edition, 1994.

[52] W. N. Raby, "Carnitine for valproic acid-induced hyperammonemia," American Journal of Psychiatry, vol. 154, no. 8, pp. 1168-1169, 1997.

[53] V. Farkas, I. Bock, J. Cseko, and A. Sandor, "Inhibition of carnitine biosynthesis by valproic acid in rats-the biochemical mechanism of inhibition," Biochemical Pharmacology, vol. 52, no. 9, pp. 1429-1433, 1996.

[54] J. C. Sackellares, S. I. Lee, and F. E. Dreifuss, "Stupor following administration of valproic acid to patients receiving other antiepileptic drugs," Epilepsia, vol. 20, no. 6, pp. 697-703, 1979.

[55] E. Harada, A. Nishiyori, Y. Tokunaga, et al., "Late-onset ornithine transcarbamylase deficiency in male patients: prognostic factors and characteristics of plasma amino acid profile," Pediatrics International, vol. 48, no. 2, pp. 105-111, 2006.

[56] J. Wadzinski, R. Franks, D. Roane, and M. Bayard, "Valproateassociated hyperammonemic encephalopathy," The Journal of the American Board of Family Medicine, vol. 20, no. 5, pp. 499502, 2007.

[57] M. Cuturic and R. K. Abramson, "Acute hyperammonemic coma with chronic valproic acid therapy," The Annals of Pharmacotherapy, vol. 39, no. 12, pp. 2119-2122, 2005.

[58] J. T. Stewart, "Treatment of valproate-induced hyperammonemia," Journal of the American Geriatrics Society, vol. 53, no. 6, p. 1080, 2005.

[59] G. E. Caughey, A. I. Vitry, A. L. Gilbert, and E. E. Roughead, "Prevalence of comorbidity of chronic diseases in Australia," BMC Public Health, vol. 8, article 221, 2008. 


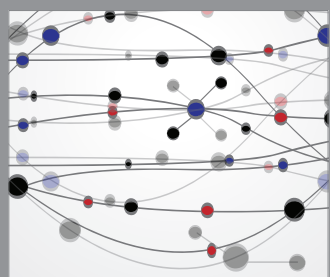

The Scientific World Journal
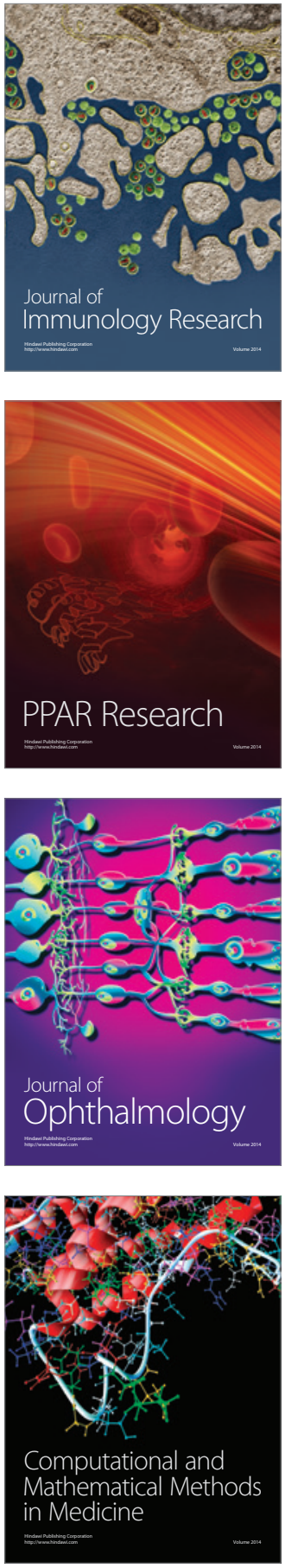

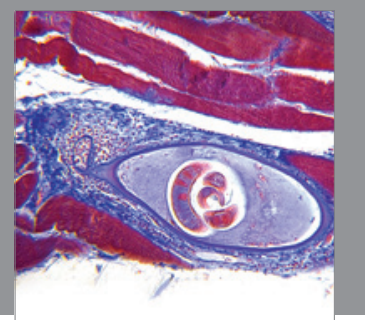

Gastroenterology

Research and Practice
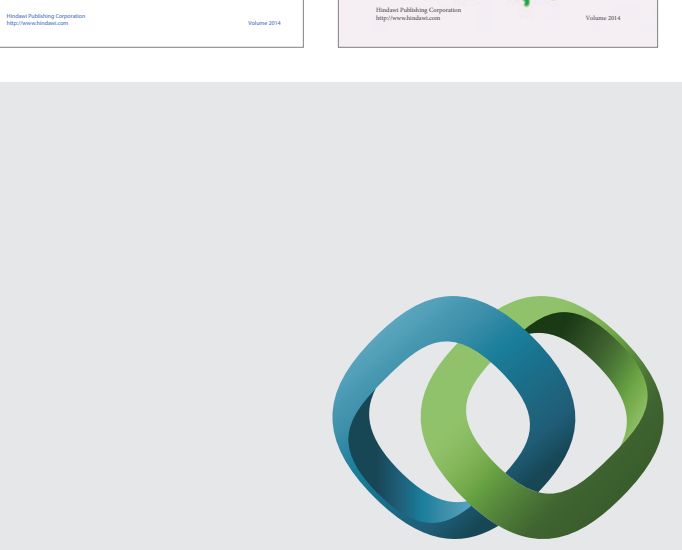

\section{Hindawi}

Submit your manuscripts at

http://www.hindawi.com
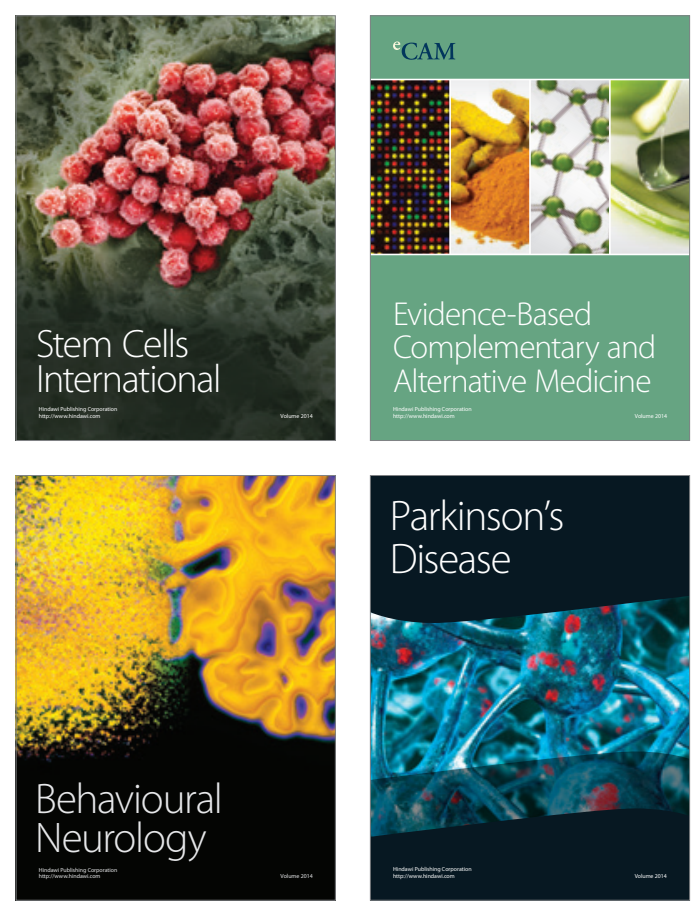

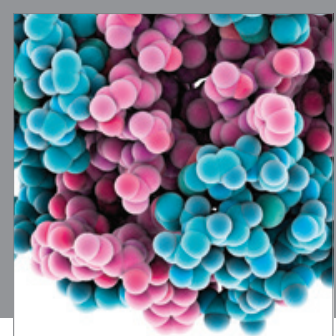

Journal of
Diabetes Research

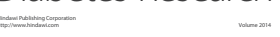

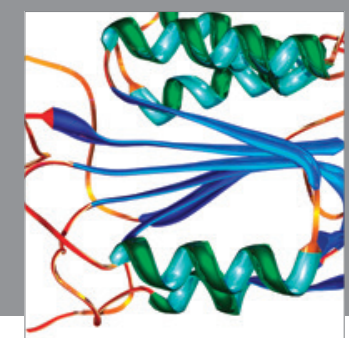

Disease Markers
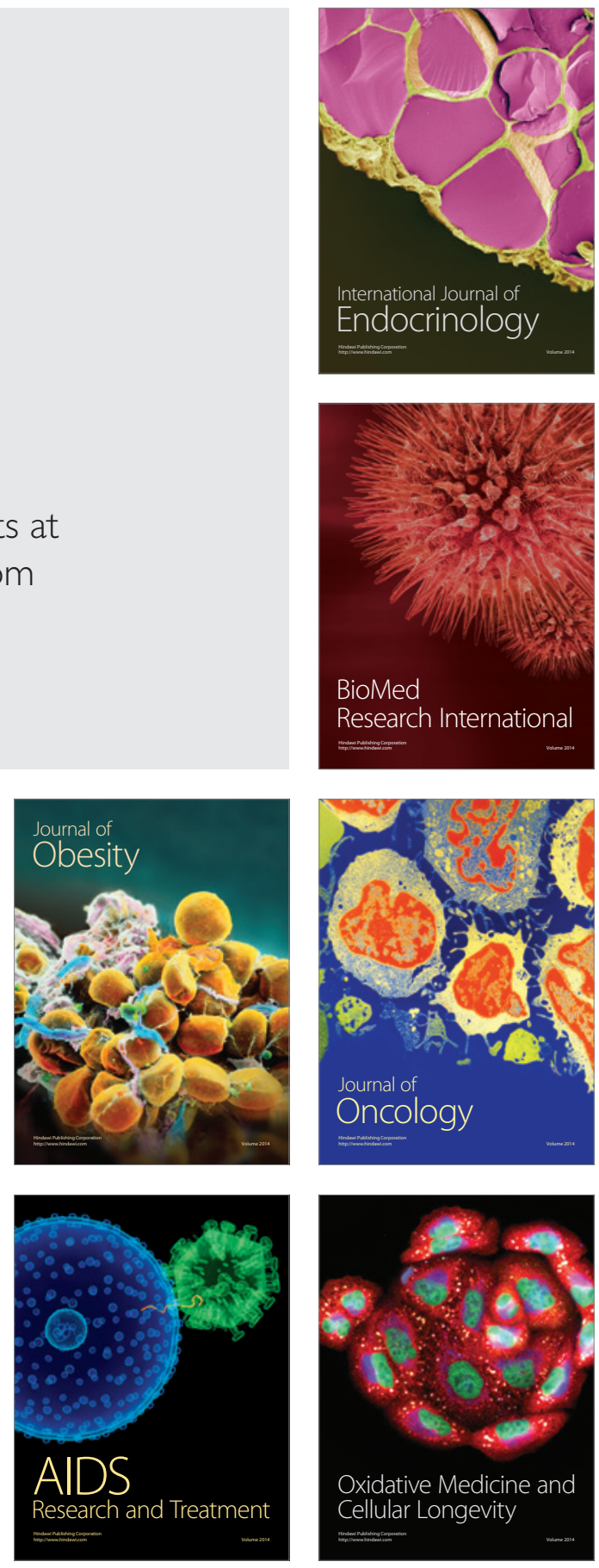